\title{
Determinants of Oral Health: Does Oral Health Literacy Matter?
}

\author{
Mohammad Mehdi Naghibi Sistani, ${ }^{1,2}$ Reza Yazdani, ${ }^{1}$ Jorma Virtanen, ${ }^{3,4}$ \\ Afsaneh Pakdaman, ${ }^{1}$ and Heikki Murtomaa ${ }^{2}$ \\ ${ }^{1}$ Department of Community Oral Health, School of Dentistry, Tehran University of Medical Sciences, P.O. Box 1439955991, \\ Tehran, Iran \\ ${ }^{2}$ Department of Oral Public Health, Institute of Dentistry, University of Helsinki, P.O. Box 41, 00014 Helsinki, Finland \\ ${ }^{3}$ Department of Public Health, University of Helsinki, P.O. Box 41, 00014 Helsinki, Finland \\ ${ }^{4}$ Department of Community Dentistry, University of Oulu, P.O. Box 5281, 90014 Oulu, Finland
}

Correspondence should be addressed to Reza Yazdani; ryazdani@sina.tums.ac.ir

Received 16 January 2013; Accepted 16 February 2013

Academic Editors: P. Gjermo and D. Wray

Copyright ( 2013 Mohammad Mehdi Naghibi Sistani et al. This is an open access article distributed under the Creative Commons Attribution License, which permits unrestricted use, distribution, and reproduction in any medium, provided the original work is properly cited.

\begin{abstract}
Objective. To evaluate oral health literacy, independent of other oral health determinants, as a risk indicator for self-reported oral health. Methods. A cross-sectional population-based survey conducted in Tehran, Iran. Multiple logistic regression analysis served to estimate the predictive effect of oral health literacy on self-reported oral health status (good versus poor) controlling for socioeconomic and demographic factors and tooth-brushing behavior. Results. In all, among 1031 participants (mean age 36.3 (SD 12.9); $51 \%$ female), women reported brushing their teeth more frequently $(P<0.001)$ and scored higher for oral health literacy (mean 10.9 versus $10.2, P<0.001)$. In the adjusted model, high age $(\mathrm{OR}=1.01,95 \% \mathrm{CI} 1.003-1.034)$, low education $(\mathrm{OR}=1.88$, 95\% CI 1.23-2.87), small living area in square meters per person ( $\mathrm{OR}=1.85,95 \%$ CI 1.003-3.423), poor tooth brushing behavior $(\mathrm{OR}=3.35,95 \% \mathrm{CI} 2.02-5.57)$, and low oral health literacy scores $(\mathrm{OR}=1.58,95 \% \mathrm{CI} 1.02-2.45)$ were significant risk indicators for poor self-reported oral health. Conclusions. Low oral health literacy level, independent of education and other socioeconomic determinants, was a predictor for poor self-reported oral health and should be considered a vital determinant of oral health in countries with developing health care systems.
\end{abstract}

\section{Introduction}

Discrepancies in oral health status result from numerous obstacles ranging from social [1], environmental [2], biological, behavioural [3], cultural, economic, and political factors $[3,4]$, to limited access to oral health care services, complicated oral health care systems, a lack of oral-healthinformation material [5], and oral heath literacy [6].

The process of acquiring oral health information, appraising its concepts, and applying oral health prevention and treatment plans appropriately requires new skill development called oral health literacy (OHL) [6]. Oral health literacy is an interplay between culture and society, the health system, education system, and oral health outcomes $[5,7]$ indicating that it may be a new determinant of oral health and should be considered more intensively in oral health research.

Although current research reveals that oral health literacy is associated with the level of education $[8,9]$, ethnic group [9,
10], dental service utilization, oral health knowledge, and oral self-care behaviour [11], but knowledge about the impact of oral health literacy on oral health outcomes is scarce $[12,13]$; moreover, little is known about this association in countries with developing health care systems such as Iran. A poor level of oral hygiene and poor oral health status are evident, especially among lower Iranian socioeconomic groups [1416].

This study therefore aimed to evaluate the role of oral health literacy as a determinant of oral health among adults in Tehran, Iran. We hypothesized that low oral health literacy level, independent of oral health socioeconomic determinants, is a risk factor for poor self-reported oral health.

\section{Materials and Methods}

2.1. Design and Data Collection. This cross-sectional population-based survey was conducted in 2011 among adults in 


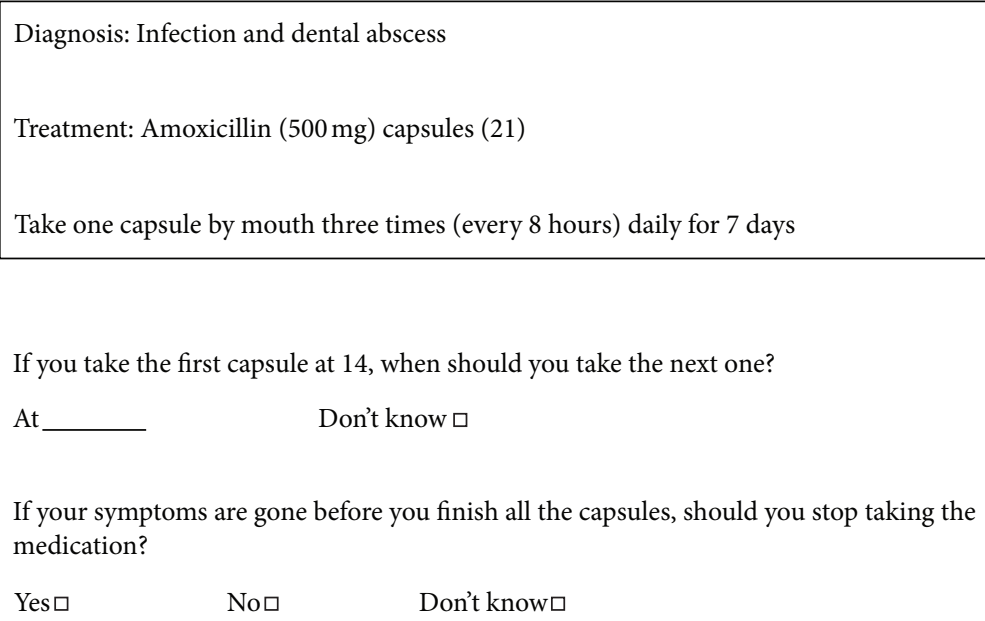

FIGURE 1: Oral health literacy adults questionnaire (OHL-AQ), amoxicillin consumption prescription.

Tehran, Iran. The Iranian Students' Polling Agency (ISPA), a professional agency, assisted in data collection. All interviewers were trained in a three-hour practical session by the main researcher in order to insure uniformity in data collection and avoid inter-interviewer variability. Training issues were related to the questions and responses, ethical considerations, and way to complete the interview-administered section of the questionnaire. Participants were interviewed at their homes.

2.2. Sampling. A stratified multistage random area served for the sampling frame. The 22 districts of Tehran were considered as strata. The samples were weighted in each stratum based on the proportion of the district population to that of the Tehran population. Within each stratum, regions were selected randomly as clusters, and then blocks were selected from each region randomly. Then ten houses in each block were selected systematically. In the final selection individuals were selected at random among all adults residing in the same house. Those unable to read or write Persian (local language) were excluded.

A sample size of 1031 was estimated by use of a samplesize calculation for estimating a single proportion $(\alpha=0.05$, the prevalence of adequate oral health literacy or $P=0.4$ obtained from pilot study [17], and design effect $=2$ ).

2.3. Measures. The following oral-health-related measures required responses: self-reported oral health, measured by asking each individual a question: "In general, how would you describe your oral health at present?" Five response categories were "excellent," "very good," "good," "fair," and "poor". For analysis we combined the categories "excellent," "very good," and "good" to yield a measure of "good self-reported oral health" and the categories "fair" and "poor" to yield a measure of "poor."

Brushing Behaviour. We asked each individual to respond to a 4-option statement indicating their tooth-brushing behaviour (rarely or never, 2 to 3 times per week, once daily, twice daily or more). For analysis, we reclassified the brushing behaviour to "less than once daily" (combining the categories of "rarely or never" and "2 to 3 times per week"), "once daily," and "twice daily or more."

Oral Health Literacy. We used the newly constructed Oral Health Literacy Adults Questionnaire (OHL-AQ) which was tested in a pilot study and showed that it is a reliable and valid questionnaire [17]. The OHL-AQ comprises four sections: reading comprehension, numeracy, listening, and decisionmaking.

The reading comprehension section consisted of six items with words omitted from one passage (3 sentences) on oral health knowledge. Of the four possible choices for each omitted word, one was correct and one choice (do not know) was added to avoid guessing or avoid missing responses. For instance, in the sentence "Brushing with toothpaste that contains [_] at least twice a [_]...... could prevent tooth decay," four options for the first omitted word were flavors, whitening agent, detergent, and fluoride, and for the second month, meal, day, and week. This section was selfadministered, with all respondents instructed to read the paragraph and fill in the blanks [17].

The numeracy section consisted of four questions related to two topics: an amoxicillin consumption prescription (2 questions) modified from the OHLI [18] and instructions for a sodium fluoride mouth rinse ( 2 questions). The prescription and instructions were added in a written box, and participants were instructed to write or select the answers (see Figure 1).

The listening section consisted of two questions about instructions after tooth extraction. This was intervieweradministered section. The interviewer read three sentences of postextraction instruction aloud twice, while participants listened and then wrote the answers. The decision-making section contained five questions related to common oral health problems and items extracted from a medical history form. Participants were instructed to read the questions and select one of four possible choices [17].

The interviewers did not help participants in reading, answering, or in conceptual meaning of items. The interviewers checked for missing items and asked the participants to 
answer those or select the "do not know" alternative. The correct answers were scored 1; the incorrect, do not know, and unanswered were scored 0 . Then, the sum of the correct answers was calculated to provide the total score for the questionnaire, ranging from 0 to 17.

Among background information acquired was demographic data comprising age, gender, and socioeconomic measures. We used years of formal education as the measure of social level. Formal education is a valid and reliable indicator for studies of association between health and social status in Iran $[19,20]$. Education was categorized into two levels: first level (1-11 years) and second (12 years and more). Economic status was assessed by living area in square meters per person $\left(\mathrm{m}^{2} / \mathrm{p}\right)$ [20]. This proxy measure was categorized into three levels: less than 20,20 to 39 , and equal to or more than 40 square meters per person living area.

2.4. Statistical Analysis. In addition to descriptive statistics, potential variation in self-reported oral health as an outcome variable was estimated by odds ratios, using multiple logistic regression while adjusting for age, gender, educational level, living area in square meters per person $\left(\mathrm{m}^{2} / \mathrm{p}\right)$, toothbrushing behavior, and oral health literacy as independent variables. We compared good self-reported oral health versus poor self-reported oral health. The significance was set at $<0.05$. All data were analysed by SPSS software for Windows (version 18).

2.5. Ethics. The ethics committee of the Tehran University of Medical Sciences approved the study. Participants were also informed before being invited to this survey about the scientific goal of this research, voluntary participation, and their right to withdraw at any time.

\section{Results}

Totally 1031 individuals participated. Characteristics of the study sample are in Table 1 . Mean age of participants was 36.3 (SD 12.9) and ranged from 18 to 65 years. Of the whole, $51.1 \%$ were female. Women reported brushing their teeth more frequently than men $\operatorname{did}(P<0.001)$ and scored higher on the oral health literacy (mean OHL-AQ 10.9 versus 10.2, $P<0.001$ ) as well. Oral health literacy scores approximated a normal distribution, 11 being the mode (Figure 2).

The results from multiple logistic regression analysis, both univariate and adjusted model, are in Table 2. High age $(\mathrm{OR}=1.01,95 \% \mathrm{CI} 1.00-1.03)$, low education (OR lowest level versus upper level $=1.88,95 \%$ CI $1.23-2.87$ ), small living area in square meters per person (OR lowest level versus upper level $=1.85,95 \%$ CI 1.00-3.42), poor tooth-brushing behavior (OR lowest level versus upper level $=3.35,95 \%$ CI 2.02-5.57), and low oral health literacy scores (OR lowest level versus upper level $=1.58,95 \%$ CI 1.02-2.45) were the most significant contributing factors to poor self-reported oral health.

\section{Discussion}

Among adults queried in Tehran, Iran, it was interesting to note that low oral health literacy level, independent of

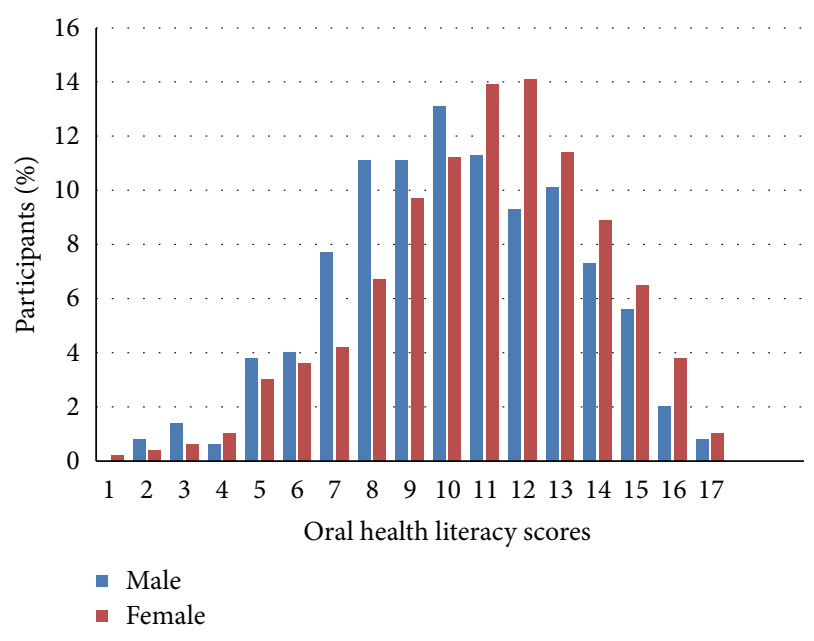

FIGURE 2: Distribution of oral health literacy adults questionnaire (OHL-AQ) scores by gender among adults in Tehran, Iran $(n=$ 1031).

education and other socioeconomic determinants, was a predictor for poor self-reported oral health.

Although the association between oral health literacy scores and self-reported oral health was confounded by other variables in the adjusted model, it reached a statistically significant level $(\mathrm{OR}=1.58,95 \% \mathrm{CI} 1.02-2.45)$; this would confirm our hypothesis that low oral health literacy level contributes to the poor self-reported oral health. Downstream outcomes like oral health status are also affected by numerous determinants other than literacy [8] such as age, education, and economic status. Our findings are in line with earlier ones which have shown that high age $[21,22]$ and low level of education $[23,24]$ are related to poor self-reported oral health.

Since income information in Iran is unreliable and Iranians usually hold more than one job at a time, we used "living area in square meters per person" as a measure of economic status. Similarly one study from Iran [20] revealed "living area in square meters per person" as demonstrating a strong correlation with mortality caused by myocardial infarction. We found that economic status was associated with self-reported oral health in the adjusted model. People who were better off rated their oral health status as better than those with suboptimal living conditions did. This finding is consistent with findings revealing socioeconomic inequalities in relation to oral health status [25-27].

Present study showed a significant association between poor self-reported oral health and lack of tooth-brushing (OR lowest level versus upper level $=3.35,95 \%$ CI 2.02-5.57). This would advocate daily tooth-brushing as an inexpensive and easy practice at individual or population level, in order to promote oral health.

Performing population studies on oral health in Iran presents several challenges. Tehran with its 8-million population has become a multicultural metropolitan area with a mixture of socioeconomic and ethnic backgrounds. A sample from Tehran (the capital), however, can at least be considered 
TABLE 1: Characteristics of the study subjects and descriptive findings by gender.

\begin{tabular}{|c|c|c|c|c|}
\hline & Total N (\%) & Male $N(\%)$ & Female $N(\%)$ & $P^{*}$ \\
\hline Age & 1030 & 504 & 526 & 0.89 \\
\hline $18-24$ & $251(24.4)$ & $126(25.0)$ & $125(23.8)$ & \\
\hline $25-44$ & $485(47.1)$ & $236(46.8)$ & $249(47.3)$ & \\
\hline $45-65$ & $294(28.5)$ & $142(28.2)$ & $152(28.9)$ & \\
\hline Mean (SD) & $36.3(12.9)$ & $36.3(13.2)$ & $36.4(12.5)$ & \\
\hline Years of education & 1022 & 500 & 522 & 0.32 \\
\hline$<12$ & $280(27.4)$ & $130(26.0)$ & $150(28.7)$ & \\
\hline$\geq 12$ & $742(72.6)$ & $370(74.0)$ & $372(71.3)$ & \\
\hline Mean (SD) & $11.9(3.8)$ & $12.1(3.7)$ & $11.6(3.9)$ & \\
\hline Living area $\left(\mathrm{m}^{2} / \mathrm{p}\right)$ & 947 & 460 & 487 & 0.80 \\
\hline$<20$ & $296(31.3)$ & $148(32.2)$ & $148(30.4)$ & \\
\hline $20-39$ & $485(51.2)$ & $234(51.9)$ & $251(51.5)$ & \\
\hline$\geq 40$ & $166(17.5)$ & $78(17.0)$ & $88(18.1)$ & \\
\hline Mean (SD) & $28.3(22.0)$ & $28.5(25.5)$ & $28.1(18.0)$ & \\
\hline Self-reported oral health status & 1013 & 498 & 515 & 0.17 \\
\hline Good & $856(84.5)$ & $413(82.9)$ & $443(86.0)$ & \\
\hline Poor & $157(15.5)$ & $85(17.1)$ & $72(14.0)$ & \\
\hline Tooth-brushing behaviour & 1029 & 504 & 525 & $<0.001$ \\
\hline Twice daily or more & $387(37.6)$ & $152(30.2)$ & $235(44.8)$ & \\
\hline Once daily & $450(43.7)$ & $223(44.2)$ & $227(43.2)$ & \\
\hline Less than once daily & $192(18.7)$ & $129(25.6)$ & $63(12.0)$ & \\
\hline Oral health literacy scores & 1030 & 504 & 526 & $<0.001$ \\
\hline $0-9$ & $358(34.8)$ & $204(40.5)$ & $154(29.3)$ & \\
\hline $10-11$ & $255(24.8)$ & $123(24.4)$ & $132(25.1)$ & \\
\hline $12-17$ & $417(40.5)$ & $177(35.1)$ & $240(45.5)$ & \\
\hline Mean (SD) & $10.5(3.0)$ & $10.2(3.0)$ & $10.9(2.9)$ & \\
\hline
\end{tabular}

${ }^{*}$ By Chi-square test.

TABLE 2: Determinants for poor self-assessed oral health based on multiple logistic regression analysis among adults in Tehran, Iran $(n=$ 1014).

\begin{tabular}{|c|c|c|c|c|}
\hline & OR $(95 \% \mathrm{CI})^{*}$ & $P$ & OR $(95 \% \mathrm{CI})^{* *}$ & $P$ \\
\hline Age (years) & $1.02(1.01-1.03)$ & $<0.001$ & $1.01(1.00-1.03)$ & 0.02 \\
\hline \multicolumn{5}{|l|}{ Gender } \\
\hline Male & 1.00 (ref.) & & 1.00 (ref.) & \\
\hline Female & $0.79(0.56-1.11)$ & 0.17 & $0.96(0.65-1.40)$ & 0.83 \\
\hline \multicolumn{5}{|l|}{ Years of education } \\
\hline$\geq 12$ & 1.00 (ref.) & & 1.00 (ref.) & \\
\hline$<12$ & $2.76(1.94-3.94)$ & $<0.001$ & $1.88(1.23-2.87)$ & 0.004 \\
\hline \multicolumn{5}{|l|}{ Living area $\left(\mathrm{m}^{2} / \mathrm{p}\right)$} \\
\hline$\geq 40$ & 1.00 (ref.) & & 1.00 (ref.) & \\
\hline $20-39$ & $1.51(0.86-2.65)$ & 0.15 & $1.57(0.87-2.83)$ & 0.12 \\
\hline$<20$ & $2.24(1.25-3.99)$ & 0.006 & $1.85(1.00-3.42)$ & 0.04 \\
\hline \multicolumn{5}{|l|}{ Oral health literacy scores } \\
\hline $12-17$ & 1.00 (ref.) & & 1.00 (ref.) & \\
\hline $10-11$ & $1.41(0.85-2.25)$ & 0.13 & $1.08(0.65-1.80)$ & 0.75 \\
\hline $0-9$ & $2.08(1.40-3.11)$ & $<0.001$ & $1.58(1.02-2.45)$ & 0.04 \\
\hline \multicolumn{5}{|l|}{ Tooth-brushing behaviour } \\
\hline Twice daily or more & 1.00 (ref.) & & 1.00 (ref.) & \\
\hline Once daily & $1.52(0.99-2.34)$ & 0.055 & $1.40(0.88-2.22)$ & 0.14 \\
\hline Less than once daily & $3.99(2.52-6.32)$ & $<0.001$ & $3.35(2.02-5.57)$ & $<0.001$ \\
\hline
\end{tabular}

* By simple regression analysis.

**Adjusted OR, goodness of fit by Hosmer and Lemeshow test $(P=0.997)$. 
representative of the urban population of Iran [28]. Access to the national health record data was impossible, and no precise data-recording exists. In order to minimize selection bias, we decided to choose a stratified multistage random area sampling and collect the data at participants' homes. This helped us to increase the response rate as well.

Social desirability in response to the self-assessment questions could cause response bias [29]. To this reason, the present results should be interpreted cautiously. They could be rather an overestimation of a participant's self-reported oral health status and oral health behavior. Some have found that self-reported oral health measures, however, can serve as a valuable tool in epidemiological studies by reducing resources and costs $[30,31]$. This measure has proven useful in evaluating dental conditions and periodontal diseases [32] or in detecting students with healthy oral status; it is more specific than sensitive [33].

\section{Conclusions}

Findings from this study indicate that poor oral health literacy was a significant risk indicator for poor self-reported oral health. It seems that oral health literacy should thus deserve recognition as an important determinant of oral health. Indeed, assessment of oral health literacy warrants attention as a priority in oral health promotion programs in countries with developing health care systems.

\section{Conflict of Interests}

The authors declare that they have no conflict of interests.

\section{Acknowledgments}

This research has been supported by Tehran University of Medical Sciences \& Health Services Grant (90-01-69-12917). The authors wish to thank Dr. A. R. Shamshiri for his contribution to data analysis and Professor A. Montazeri for his contribution in drafting and commenting on the paper.

\section{References}

[1] J. Vanobbergen, L. De Visschere, M. Daems, A. Ceuppens, and J. van Emelen, "Sociodemographic determinants for oral health risk profiles," International Journal of Dentistry, vol. 2010, Article ID 938936, 4 pages, 2010.

[2] J. T. Newton and E. J. Bower, "The social determinants of oral health: new approaches to conceptualizing and researching complex causal networks," Community Dentistry and Oral Epidemiology, vol. 33, no. 1, pp. 25-34, 2005.

[3] D. L. Patrick, R. S. Y. Lee, M. Nucci, D. Grembowski, C. Z. Jolles, and P. Milgrom, "Reducing oral health disparities: a focus on social and cultural determinants," BMC Oral Health, vol. 6, supplement 1, article S4, 2006.

[4] P. E. Petersen, "The World Oral Health Report 2003: continuous improvement of oral health in the 21st century-the approach of the WHO Global Oral Health Programme," Community Dentistry and Oral Epidemiology, vol. 31, supplement 1, pp. 324, 2003.
[5] National Institute of Health (NIH), "The invisible barrier: Literacy and its relationship with oral health. A report of a workgroup sponsored by the national institute of dental and craniofacial research, national institutes of health," Journal of Public Health Dentistry, vol. 65, no. 3, pp. 174-182, 2005.

[6] A. M. Horowitz and D. V. Kleinman, "Oral health literacy: a pathway to reducing oral health disparities in Maryland," Journal of Public Health Dentistry, vol. 72, supplement 1, pp. S26-S30, 2012.

[7] A. M. Horowitz and D. V. Kleinman, "Oral health literacy: the new imperative to better oral health," Dental Clinics of North America, vol. 52, no. 2, pp. 333-344, 2008.

[8] M. Jones, J. Y. Lee, and R. Gary Rozier, "Oral health literacy among adult patients seeking dental care," Journal of the American Dental Association, vol. 138, no. 9, pp. 1199-1208, 2007.

[9] K. A. Atchison, M. W. Gironda, D. Messadi, and C. DerMartirosian, "Screening for oral health literacy in an urban dental clinic," Journal of Public Health Dentistry, vol. 70, no. 4, pp. 269-275, 2010.

[10] J. Y. Lee, K. Divaris, A. D. Baker, R. G. Rozier, S. Y. D. Lee, and W. F. Vann, "Oral health literacy levels among a low-income WIC population," Journal of Public Health Dentistry, vol. 71, no. 2, pp. 152-160, 2011.

[11] E. J. Parker and L. M. Jamieson, "Associations between Indigenous Australian oral health literacy and self-reported oral health outcomes," BMC Oral Health, vol. 10, no. 1, article 3, 2010.

[12] H. M. Wong, S. M. Bridges, C. K. Yiu, C. P. McGrath, T. K. $\mathrm{Au}$, and D. S. Parthasarathy, "Development and validation of Hong Kong rapid estimate of adult literacy in dentistry," Journal of Investigative and Clinical Dentistry, vol. 3, no. 2, pp. 118-127, 2012.

[13] R. G. Rozier, "Commentary on 'oral health literacy: a pathway to reducing oral health disparities in Maryland"' Journal of Public Health Dentistry, vol. 72, supplement 1, pp. S32-S33, 2012.

[14] H. Hessari, M. M. Vehkalahti, M. J. Eghbal, and H. T. Murtomaa, "Oral health among 35- to 44-year-old Iranians," Medical Principles and Practice, vol. 16, no. 4, pp. 280-285, 2007.

[15] R. Yazdani, M. M. Vehkalahti, M. Nouri, and H. Murtomaa, "Oral health and treatment needs among 15-year-olds in Tehran, Iran," Community Dental Health, vol. 25, no. 4, pp. 221225, 2008.

[16] S. Z. Mohebbi, J. I. Virtanen, M. Vahid-Golpayegani, and M. M. Vehkalahti, "Early childhood caries and dental plaque among 1-3-year-olds in Tehran, Iran," Journal of Indian Society of Pedodontics and Preventive Dentistry, vol. 24, no. 4, pp. 177-181, 2006.

[17] M. M. Naghibi Sistani, A. Montazeri, R. Yazdani, and H. Murtomaa, "A new oral health literacy instrument for public health: development and pilot testing," Journal of Investigative and Clinical Dentistry. In press.

[18] D. A. Sabbahi, H. P. Lawrence, H. Limeback, and I. Rootman, "Development and evaluation of an oral health literacy instrument for adults," Community Dentistry and Oral Epidemiology, vol. 37, no. 5, pp. 451-462, 2009.

[19] A. Montazeri, A. Goshtasebi, and M. Vahdaninia, "Educational inequalities in self-reported health in a general Iranian population," BMC Research Notes, vol. 1, article 50, 2008.

[20] T. Donyavi, K. H. Naieni, S. Nedjat, M. Vahdaninia, M. Najafi, and A. Montazeri, "Socioeconomic status and mortality after acute myocardial infarction: a study from Iran," International Journal for Equity in Health, vol. 10, article 9, 2011. 
[21] S. Engström and A. Holmlund, "Self-estimated oral and general health are related and associated with clinically investigated dental health," Swedish Dental Journal, vol. 35, no. 4, pp. 169175, 2011.

[22] M. P. Pattussi, K. G. Peres, A. F. Boing, M. A. Peres, and J. S. D. Da Costa, "Self-rated oral health and associated factors in Brazilian elders," Community Dentistry and Oral Epidemiology, vol. 38, no. 4, pp. 348-359, 2010.

[23] W. Sabbah, G. Tsakos, T. Chandola, A. Sheiham, and R. G. Watt, "Social gradients in oral and general health," Journal of Dental Research, vol. 86, no. 10, pp. 992-996, 2007.

[24] E. Bernabé, A. L. Suominen, A. Nordblad et al., "Education level and oral health in Finnish adults: evidence from different lifecourse models," Journal of Clinical Periodontology, vol. 38, no. 1, pp. 25-32, 2011.

[25] T. Somkotra, "Socioeconomic inequality in self-reported oral health status: the experience of Thailand after implementation of the universal coverage policy," Community Dental Health, vol. 28, no. 2, pp. 136-142, 2011.

[26] V. Ravaghi, M. Underwood, V. Marinho, and S. Eldridge, "Socioeconomic status and self-reported oral health in Iranian adolescents: the role of selected oral health behaviors and psychological factors," Journal of Public Health Dentistry, vol. 72, no. 3, pp. 198-207, 2012.

[27] W. Sabbah, G. Tsakos, A. Sheiham, and R. G. Watt, “The role of health-related behaviors in the socioeconomic disparities in oral health," Social Science and Medicine, vol. 68, no. 2, pp. 298303, 2009.

[28] A. Montazeri, A. Goshtasebi, M. Vahdaninia, and B. Gandek, "The Short Form Health Survey (SF-36): translation and validation study of the Iranian version," Quality of Life Research, vol. 14, no. 3, pp. 875-882, 2005.

[29] O. Sjöström and D. Holst, "Validity of a questionnaire survey: response patterns in different subgroups and the effect of social desirability," Acta Odontologica Scandandinavica, vol. 60, no. 3, pp. 136-140, 2002.

[30] K. Buhlin, A. Gustafsson, K. Andersson, J. Håkansson, and B. Klinge, "Validity and limitations of self-reported periodontal health," Community Dentistry and Oral Epidemiology, vol. 30, no. 6, pp. 431-437, 2002.

[31] B. Blicher, K. Joshipura, and P. Eke, "Validation of self-reported periodontal disease: a systematic review," Journal of Dental Research, vol. 84, no. 10, pp. 881-890, 2005.

[32] C. Pinelli and L. Castro Monteiro Loffredo, "Reproducibility and validity of self-perceived oral health conditions," Clinical Oral Investigations, vol. 11, no. 4, pp. 431-437, 2007.

[33] R. Yazdani, M. M. Vehkalahti, M. Nouri, and H. Murtomaa, "Validity of self-assessment of oral health among 15-year-olds in Tehran, Iran," Oral Health \& Preventive Dentistry, vol. 6, no. 4, pp. 263-269, 2008. 


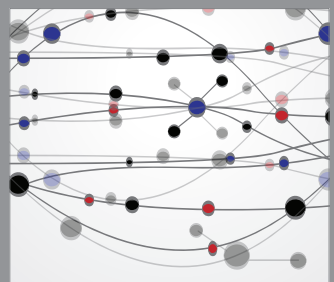

The Scientific World Journal
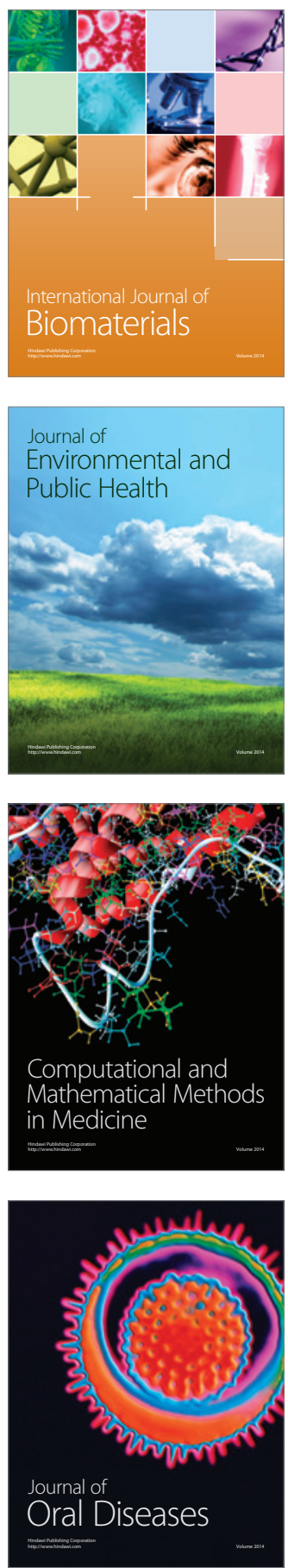
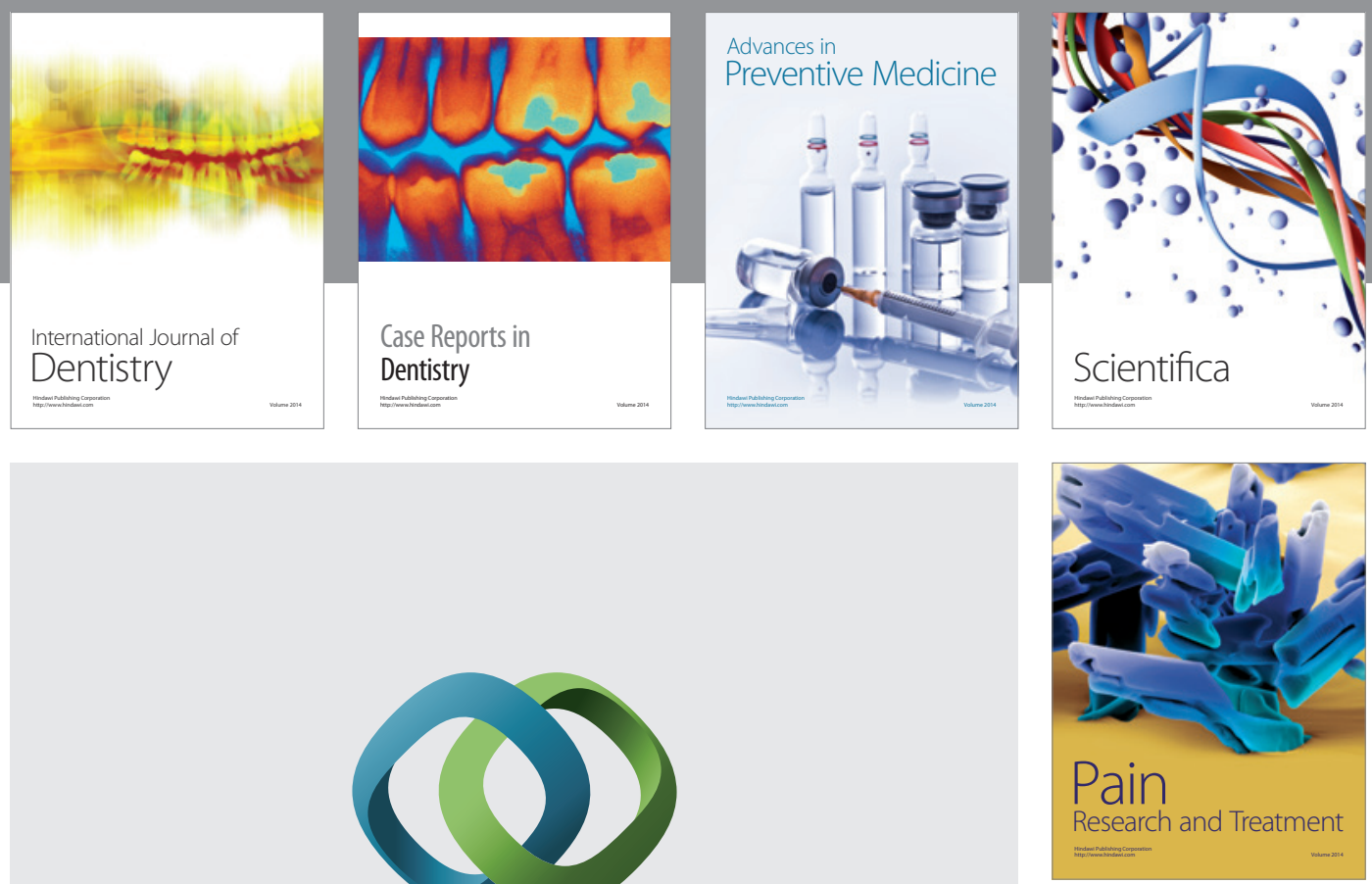

\section{Hindawi}

Submit your manuscripts at

http://www.hindawi.com
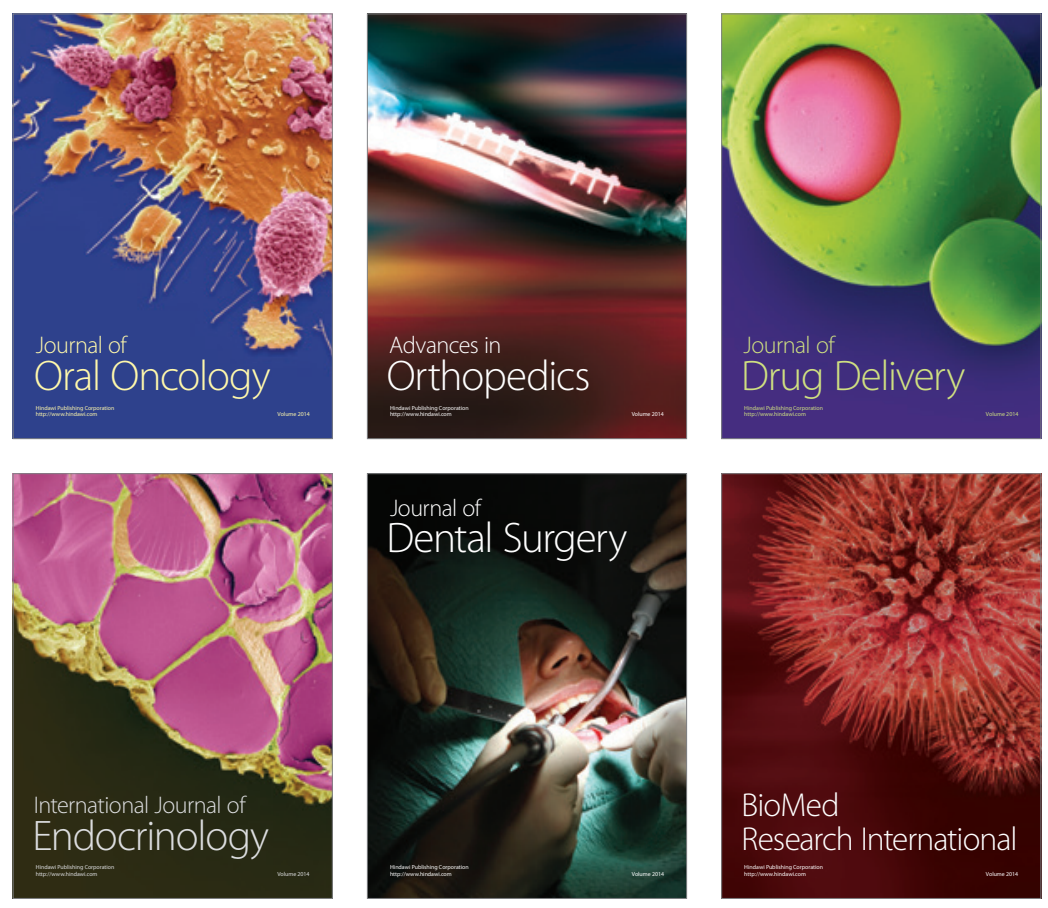

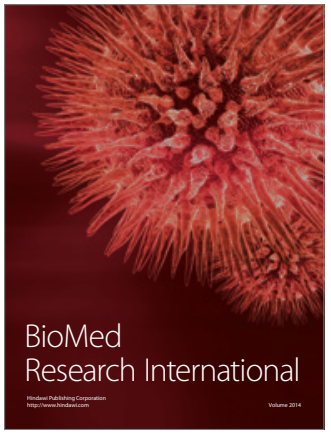

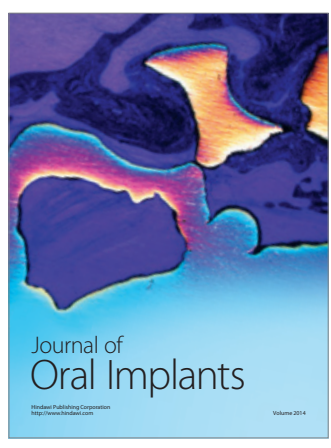
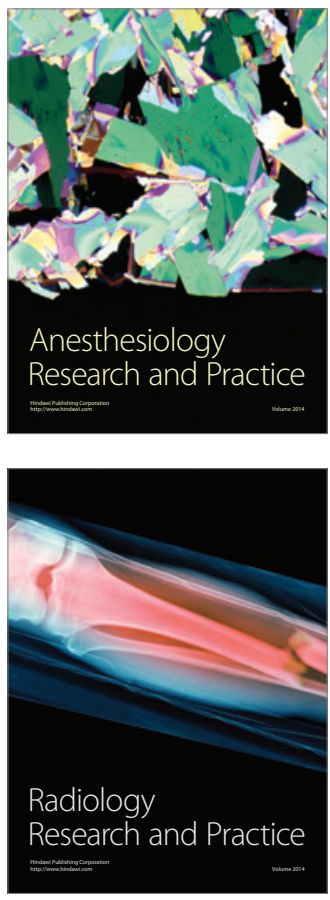